\title{
Predicting invasion in grassland ecosystems: is exotic dominance the real embarrassment of richness?
}

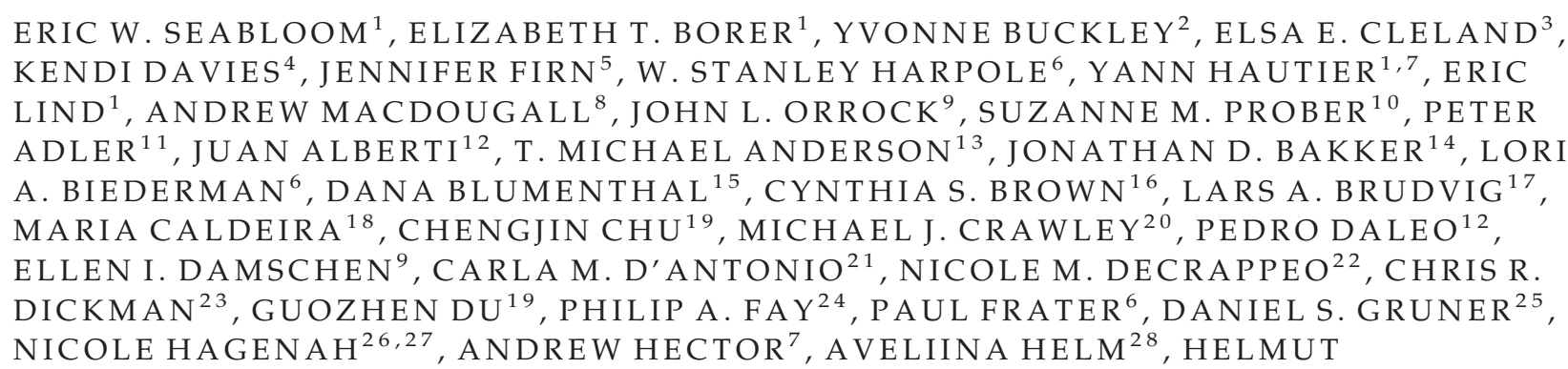
HILLEBRAND ${ }^{29}$, KIRSTEN S. HOFMOCKEL ${ }^{6}$, HOPE C. HUMPHRIES ${ }^{30}$, OSCAR IRIBARNE ${ }^{12}$, VIRGINIA L. JIN ${ }^{31}$, ADAM KAY ${ }^{32}$, KEVIN P. KIRKMAN ${ }^{26}$, JULIA A. KLEIN ${ }^{33}$, JOHANNES M. H. KNOPS ${ }^{34}$, KIMBERLY J. LA PIERRE ${ }^{27}$, LAURA M. LADWIG ${ }^{35}$, JOHN G. LAMBRINOS ${ }^{36}$, ANDREW D. B. LEAKEY ${ }^{37}$, QI LI ${ }^{38}$, WEI LI ${ }^{39}$, REBECCA MCCULLEY ${ }^{40}$, BRETT MELBOURNE ${ }^{4}$, CHARLES E. MITCHELL ${ }^{41}$, JOSLIN L. MOORE ${ }^{42}$, JOHN MORGAN ${ }^{43}$, BRENT MORTENSEN ${ }^{6}$, LYDIA R. O’HALLORAN ${ }^{4}{ }^{4}$, MEELIS PÄRTEL ${ }^{28}$, JESÚS PASCUAL ${ }^{12}$, DAVID A. PYKE ${ }^{22}$, ANITA C. RISCH ${ }^{45}$, ROBERTO SALGUERO-GÓMEZ ${ }^{2}$, MAHESH SANKARAN ${ }^{46}$, MARTIN SCHUETZ $^{45}$, ANNA SIMONSEN ${ }^{47}$, MELINDA SMITH $^{48}$, CARLY $^{2}$ STEVENS ${ }^{49}$, LAUREN SULLIVAN ${ }^{6}$, GLENDA M. WARDLE ${ }^{23}$, ELIZABETH M.WOLKOVICH ${ }^{50}$, PETER D. WRAGG ${ }^{1}$, JUSTIN WRIGHT ${ }^{51}$ and LOUIE YANG ${ }^{52}$

${ }^{1}$ Department of Ecology, Evolution, and Behavior, University of MN, St. Paul, MN 55108, USA, ${ }^{2}$ ARC Centre of Excellence for Environmental Decisions, School of Biological Sciences, The University of Queensland, Brisbane, Queensland 4072, Australia, ${ }^{3}$ Ecology, Behavior \& Evolution Section, University of California, San Diego, La Jolla, CA 92093, USA, ${ }^{4}$ Department of Ecology and Evolutionary Biology, University of Colorado, Boulder, CO 80309, USA, ${ }^{5}$ Queensland University of Technology, Biogeosciences, Brisbane, Queensland 4000, Australia, ${ }^{6}$ Department of Ecology, Evolution, and Organismal Biology, Iowa State University, Ames, IA 50011, USA, ${ }^{7}$ Institute of Evolutionary Biology and Environmental Studies, University of Zurich, Winterthurerstrasse 190, CH-8057, Zurich, Switzerland, ${ }^{8}$ Department of Integrative Biology, University of Guelph, Guelph, Ontario N1G 2W1, Canada, ${ }^{9}$ Department of Zoology, University of Wisconsin, Madison, WI 53706, USA, ${ }^{10}$ CSIRO Ecosystem Sciences, Private Bag 5, Wembley, WA 6913, Australia, ${ }^{11}$ Department of Wildland Resources and the Ecology Center, Utah State University, Logan, UT 84322, USA, ${ }^{12}$ Instituto de Investigaciones Marinas y Costeras (UNMdP-CONICET), Mar del Plata, Argentina, ${ }^{13}$ Department of Biology, Wake Forest University, Winston-Salem, NC 27109, USA, ${ }^{14}$ School of Environmental and Forest Sciences, University of Washington, Seattle, WA 98195-4115, USA, ${ }^{15}$ Rangeland Resources Research Unit, USDA Agricultural Research Service, Fort Collins, CO 80526, USA, ${ }^{16}$ Department of Bioagricultural Sciences and Pest Management, Colorado State University, Fort Collins, CO 80523, USA, ${ }^{17}$ Department of Plant Biology, Michigan State University, East Lansing, MI 48824, USA, ${ }^{18}$ Centro de Estudos Florestais, Instituto Superior de Agronomia, Technical University of Lisbon, Lisbon, Portugal, ${ }^{19}$ School of Life Sciences, Lanzhou University, Lanzhou 730000, China, ${ }^{20}$ Department of Biology, Imperial College London, Silwood Park, Ascot SL5 7PY, UK, ${ }^{21}$ Department of Ecology, Evolution and Marine Biology, University of California, Santa Barbara, CA 93106, USA, ${ }^{22}$ U.S. Geological Survey Forest and Rangeland Ecosystem Science Center, Corvallis, OR 97331, USA, ${ }^{23}$ Desert Ecology Research Group, School of Biological Sciences, University of Sydney, Sydney, NSW 2006, Australia, ${ }^{24}$ USDA-ARS Grassland Soil and Water Research Lab, Temple, TX 76502, USA, ${ }^{25}$ Department of Entomology, University of Maryland, College Park, MD 20742, USA, ${ }^{26}$ School of Life Sciences, University of KwaZulu-Natal, Scottsville, Pietermaritzburg 3209, South Africa, ${ }^{27}$ Department of Ecology, Evolutionary Biology, Yale University, New Haven, CT 06520, USA, ${ }^{28}$ Institute of Ecology and Earth Sciences, University of Tartu, Tartu, Estonia, ${ }^{29}$ Institute for Chemistry and Biology of the Marine Environment, Carl-von-Ossietzky University, Wilhelmshaven, Germany, ${ }^{30}$ INSTAAR, University of Colorado, Boulder, CO 80309-0450, USA, ${ }^{31}$ USDA-ARS Agroecosystem Management Research Unit, Lincoln, NE 68583, USA, ${ }^{32}$ Biology Department, University of St. Thomas, Saint Paul, MN 55105, USA, ${ }^{33}$ Department Forest, Rangeland \& Watershed Stewardship, Colorado State University, Fort Collins, CO 80523-1472, USA, ${ }^{34}$ School of Biological Sciences, University of Nebraska, Lincoln, NE 68588, USA, ${ }^{35}$ Department of Biology, University of New Mexico, Albuquerque, NM 87103, USA, ${ }^{36}$ Department of Horticulture, Oregon State University, Corvallis, OR 97331, USA, ${ }^{37}$ Department of Plant Biology and Institute for Genomic Biology, University of Illinois at Urbana-Champaign, Urbana, IL 61801, USA, ${ }^{38}$ Key Laboratory of Adaptation and Evolution of 
Plateau Biota, Northwest Institute of Plateau Biology, Chinese Academy of Sciences, Xining 810008, Qinghai, China, ${ }^{39}$ Yunnan Academy of Biodiversity, Southwest Forestry University, Kunming 650224, China, ${ }^{40}$ Department of Plant $\mathcal{E}$ Soil Sciences, University of Kentucky, Lexington, KY 40546, USA, ${ }^{41}$ Department of Biology, University of North Carolina, Chapel Hill, NC 27599, USA, ${ }^{42}$ Australian Research Centre for Urban Ecology, Melbourne, c/o School of Botany, University of Melbourne, Melbourne, Victoria 3010, Australia, ${ }^{43}$ Department of Botany, La Trobe University, Bundoora 3086, Victoria, Australia, ${ }^{44}$ Department of Zoology, Oregon State University, Corvallis, OR 97331, USA, ${ }^{45}$ Swiss Federal Institute for Forest, Snow and Landscape Research, 8903 Birmensdorf, Switzerland, ${ }^{46}$ National Centre for Biological Sciences, GKVK Campus, Bellary Road, Bangalore 560065, India, ${ }^{47}$ Department of Ecology E Evolutionary Biology, University of Toronto, Toronto, ON M5S 3B2, Canada, ${ }^{48}$ Department of Biology, Colorado State University, Fort Collins, CO 80523, USA, ${ }^{49}$ Lancaster Environment Center, Lancaster University, Lancaster LA1 4YQ, UK, ${ }^{50}$ Biodiversity Research Centre, University of British Columbia, Vancouver V6T 1Z4, Canada, ${ }^{51}$ Department of Biology, Duke University, Durham, NC 27708, USA, ${ }^{52}$ Department of Entomology, University of California, Davis, CA 95616, USA

\begin{abstract}
Invasions have increased the size of regional species pools, but are typically assumed to reduce native diversity. However, global-scale tests of this assumption have been elusive because of the focus on exotic species richness, rather than relative abundance. This is problematic because low invader richness can indicate invasion resistance by the native community or, alternatively, dominance by a single exotic species. Here, we used a globally replicated study to quantify relationships between exotic richness and abundance in grass-dominated ecosystems in 13 countries on six continents, ranging from salt marshes to alpine tundra. We tested effects of human land use, native community diversity, herbivore pressure, and nutrient limitation on exotic plant dominance. Despite its widespread use, exotic richness was a poor proxy for exotic dominance at low exotic richness, because sites that contained few exotic species ranged from relatively pristine (low exotic richness and cover) to almost completely exotic-dominated ones (low exotic richness but high exotic cover). Both exotic cover and richness were predicted by native plant diversity (native grass richness) and land use (distance to cultivation). Although climate was important for predicting both exotic cover and richness, climatic factors predicting cover (precipitation variability) differed from those predicting richness (maximum temperature and mean temperature in the wettest quarter). Herbivory and nutrient limitation did not predict exotic richness or cover. Exotic dominance was greatest in areas with low native grass richness at the site- or regional-scale. Although this could reflect native grass displacement, a lack of biotic resistance is a more likely explanation, given that grasses comprise the most aggressive invaders. These findings underscore the need to move beyond richness as a surrogate for the extent of invasion, because this metric confounds monodominance with invasion resistance. Monitoring species' relative abundance will more rapidly advance our understanding of invasions.
\end{abstract}

Received 22 April 2013; revised version received 16 July 2013 and accepted 14 August 2013

'It is not only winds, currents, and birds that aid the migration of plants; man primarily takes care of this' (Von Humboldt, 1805).

\section{Introduction}

Human commerce and migration have breached biogeographic barriers, initiating an unprecedented period of global species migration and homogenization that has intrigued biologists for over 200 years (Von Humboldt, 1805; Candolle \& Sprengel, 1821; Darwin, 1859; Elton, 1958; Mooney \& Cleland, 2001; Levine \& D' Antonio, 2003; Mack, 2003; Qian \& Ricklefs, 2006). Introduced species currently comprise $20 \%$ of some continental floras and $60-80 \%$ of some island floras (Vitousek et al., 1997). Invasions can alter basic ecosystem processes, such as water and nutrient cycling, fire frequency, and sediment transport (Vitousek, 1990;

Correspondence: Eric Seabloom, tel. + 6126243406 ,

fax + 612624 6777, e-mail: seabloom@umn.edu
Lodge, 1993; Mills et al., 1994; Seabloom \& Wiedemann, 1994; Vitousek et al., 1997; Levine et al., 2003), and the associated losses in ecosystem goods and services have been valued at almost 120 billion dollars per year in the United States alone (Pimentel et al., 2005). Although exotic species dominate some ecosystems, other ecosystems remain dominated by native species (Von Humboldt, 1805; Candolle \& Sprengel, 1821; Darwin, 1859; Elton, 1958; Mack, 1989), raising a broadly relevant ecological question: why do exotic plants dominate some locations while other locations remain largely pristine? Centuries after it was posed, this question remains unresolved largely due to lack of comprehensive, standardized data collected globally across a diversity of community types.

The distribution of invasions may reflect the historical contingencies of evolution, or it may arise determin- 
istically. For example, species that evolved on large and species-rich continents may be inherently competitively superior (Darwin, 1859; Sax \& Brown, 2000; Van Kleunen et al., 2011), and recent work has shown that a single suite of European species dominates many invaded grasslands worldwide (Firn et al., 2011). Conversely, some ecosystems may be particularly vulnerable to invasion, such as those with low diversity or high levels of disturbance, grazing, introduction of exotic species, or human activity (Crawley, 1987; Davis et al., 2000; Sax \& Brown, 2000; Shea \& Chesson, 2002; Rejmanek, 2003; Seabloom et al., 2006; Melbourne et al., 2007).

Selection during the invasion process also may create strong biases in exotic species' traits that give the exotics a preferential advantage in certain environments (Seabloom et al., 2006; Gonzalez et al., 2010; Van Kleunen et al., 2011). For example, species that are well adapted to human-dominated landscapes are more likely to be introduced by human colonists either intentionally (e.g., domestic plants and animals) or unintentionally (e.g., weeds, pests, and pathogens) (Von Humboldt, 1805; Candolle \& Sprengel, 1821; Mack, 1989, 2003; Sax \& Brown, 2000) and thus may become invasive when introduced into human-dominated landscapes with high nutrient supply rates, grazing, or disturbance (Mack, 1989; Davis et al., 2000; Parker et al., 2006; Seabloom et al., 2009; Gonzalez et al., 2010; Antonelli et al., 2011). To the degree that invasions arise as a result of human alteration of an ecosystem, the success of species invasions may be more driven by a species' ability to exploit human-dominated landscapes as opposed to the direct effect of a species' provenance.

Syntheses and meta-analyses have found that exotic richness is often higher in fertile areas where human population, economic activity, habitat conversion, and species introduction rates are the highest (Balmford et al., 2001; Scott et al., 2001; Sax et al., 2002; Rejmanek, 2003; Taylor \& Irwin, 2004; Williams et al., 2005; Seabloom et al., 2006; Fridley et al., 2007). However, we currently have little understanding of the patterns of exotic dominance, even though it is likely to be functionally more significant than richness (Lodge, 1993; Mills et al., 1994; Seabloom \& Wiedemann, 1994; Vitousek et al., 1997; Parker et al., 1999; Levine et al., 2003), because dominant species have the highest impact on essential ecosystem functions such as primary productivity (Hurlbert, 1997; Grime, 1998). This focus on exotic richness is driven mostly by data availability rather than conservation priorities that often recognize the importance of exotic abundance (Catford et al., 2012).

Many exotic species are relatively benign and their establishment may result in a net increase in diversity with negligible impacts on the native community (Sax et al., 2002; Davis, 2003; Firn et al., 2011). In contrast, notorious invaders (e.g., spotted knapweed, purple loosestrife, and kudzu) may occur in nearly monospecific stands, and the highest dominance of exotics can occur at sites with low exotic diversity due to the presence of one or two highly aggressive species (Catford et al., 2012). Thus, although it is often used as a proxy (e.g., Vitousek et al., 1997; Seabloom et al., 2006), we hypothesize that exotic richness is a highly inconsistent predictor of exotic dominance. Furthermore, we expect a nonlinear relationship, as exotic richness is bounded at 0 species, and relative exotic cover (exotic cover divided by total cover) is bounded between 0 and $100 \%$.

We focus on herbaceous-dominated ecosystems (e.g., grasslands, steppes, old fields, and pastures), because they are globally distributed and play a key role in the biosphere. Grasslands account for about 35\% of the Earth's ice-free land mass and net primary production (Chapin et al., 2002; Conant, 2010). With widespread conversion for multiple anthropogenic uses, including $70 \%$ of global agriculture, grasslands rank among the most critically endangered biomes (Hoekstra et al., 2005; Ramankutty et al., 2008; Henwood, 2010). Grasslands provide an opportunity to examine fundamental processes that underlie global patterns of invasion. Within the span of the last two centuries, exotic species have overtaken vast expanses of grasslands in Australia, South America, and parts of North America (Mack \& Thompson, 1982; Mack, 1989; Firn et al., 2011). In contrast, other areas have apparently remained resistant to invasion (e.g., southern Africa and the central North American Great Plains) (Mack \& Thompson, 1982).

We start by examining the relationship between exotic species establishment (exotic richness) and dominance (exotic cover) and test whether exotic richness, a measure widely used in global analyses of exotic invasion (Fridley et al., 2004; Catford et al., 2012), is a reasonable surrogate for exotic dominance. We then quantify variability in exotic cover that is associated with biogeographic regions (i.e., subcontinents) and ecosystem types (e.g., annual grasslands, mesic grasslands, or alpine tundra). We then test whether this variability is associated with the following factors that have been hypothesized or demonstrated to mediate the establishment or dominance of exotic species: (i) human land use (e.g., agricultural history and proximity to roads, towns, and rivers) (Gelbard \& Harrison, 2003; Rejmanek, 2003; Seabloom et al., 2006); (ii) environmental gradients (e.g., precipitation, elevation, and aboveground biomass) (Balmford et al., 2001; Williams et al., 2005; Seabloom et al., 2006); (iii) diversity or composition of the native flora (e.g., total diversity and diversity of key species groups) (Fargione et al., 2003; Stohlgren et al., 2003; Fridley et al., 2007); (iv) herbivore pressure (change in biomass in response to excluding vertebrate 
herbivores) (Mack, 1989; Seabloom et al., 2005, 2009; Parker et al., 2006); and (v) nutrient limitation (change in biomass in response to fertilization) (Huenneke et al., 1990; Davis et al., 2000; Seabloom, 2007). We use the results of experimental nutrient additions and fencing treatments to directly assess nutrient limitation and herbivore pressure.

\section{Materials and methods}

\section{Study system}

This research is conducted within the context of the Nutrient Network (NutNet), a globally replicated study of grassland ecosystems. The data in this study are collected from 62 sites located in 13 countries (Argentina, Australia, Canada, China, Estonia, Germany, India, Portugal, South Africa, Switzerland, Tanzania, United Kingdom, United States) on six continents [Australia $(N=7)$, Africa $(N=4)$, Asia $(N=2)$, Europe $(N=9)$, North America $(N=39)$, South America $(N=1)$; Fig. 1, Table S1]. We had the highest replication in North America, and these sites also had a large degree of variation in their degree of invasion. We account for within-continent variability with a regional categorical variable nested within continent. Specifically, we divided the North American sites into four regions based on longitudinal mountain ranges (Sierras/ Cascades, Rockies, and Appalachians): Pacific Coast, Intermountain-West, Central, and Atlantic Coast. These regions broadly correspond with the regions of temperate grasslands and invasions used by Mack (1989) and the biomes used by Olson et al. (2001).

Sites were selected without respect to the dominance of native or exotic species. All sites are dominated by herbaceous species and represent a wide range of ecosystem types including alpine tundra, annual grasslands, mesic grasslands, montane meadows, old fields, salt marshes, savanna, semiarid grasslands, shortgrass prairie, shrub steppes, and tallgrass prairie. Sites span wide ranges of elevation (0$4241 \mathrm{~m})$, mean annual precipitation (211-2072 $\left.\mathrm{mm} \mathrm{yr}^{-1}\right)$, mean annual temperature $(0.3-23.7 \mathrm{C})$, latitude $\left(38^{\circ} \mathrm{S}-59^{\circ} \mathrm{N}\right)$, and aboveground productivity (26-1408 $\mathrm{g} \mathrm{m}^{-2} \mathrm{yr}^{-1}$ ).

The lead scientist at each site provided latitude and elevation data, and climate data for each site were derived from the WorldClim database (version 1.4; http://www.worldclim. org/bioclim) (Hijmans et al., 2005). In our models we used the following climate variables (BIO designator indicates the variable code in the WorldClim database): mean annual temperature (degrees $\mathrm{C}$; BIO1), mean maximum temperature of the warmest month (BIO5), mean minimum temperature of the coldest month (BIO6), mean annual precipitation ( $\mathrm{mm}$ per year; BIO12), precipitation seasonality (coefficient of variation in precipitation among months; BIO15), temperature seasonality (SD of temperature among months; $\mathrm{BIO} 4$ ), mean temperature in the wettest quarter (degrees C; BIO8). This suite of climate variable summarizes the mean and seasonality of temperature and precipitation and the seasonal synchrony of rainfall and temperature (i.e., does most of the rain fall during hot or cool times of the year?).

In addition, each scientist provided detailed data on the agricultural history of each site. Here we included two variables summarizing the cultivation and grazing history of each site. To do this, we created an ordered variable summarizing the time as each site had been grazed by domestic livestock: (0) Never grazed, (1) 30 or more years since grazing, (2) 10-29 years since grazing, (3) 1-9 years since grazing, and (4) Currently grazed. We constructed a similar metric for cultivation with the following categories: (0) Never cultivated, (1) 30
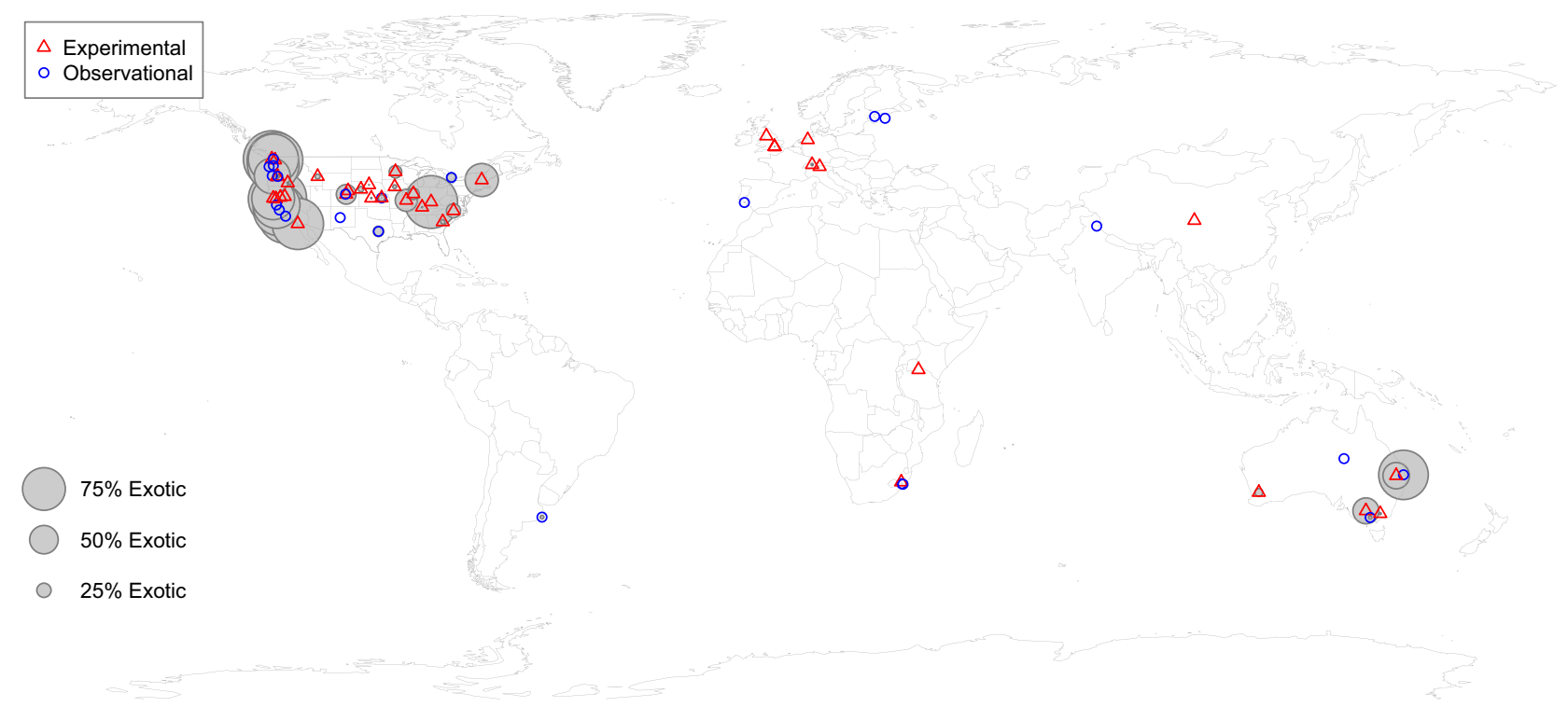

Fig. 1 Nutrient Network sites included in the current analyses. Observational sites only have a single year of data and no experimental manipulations. Experimental sites have 1 year of pretreatment data in addition to data after the start of the fencing and nutrientaddition treatments. Gray-shaded circles are proportional to exotic cover. 
or more years since cultivation, and (2) less than 30 years since cultivation. We used aerial photos of each site (maps.google.com) to assess geographic features associated with invasion including distance to the nearest road, coast, and river, and cultivated land as well as the population of the nearest town or city. Proximity to coastlines, rivers, roads, agricultural land, and human populations centers have all been associated with species invasions (Forman \& Alexander, 1998; Rejmanek, 2003; Small \& Cohen, 2004; Taylor \& Irwin, 2004; Seabloom et al., 2006; Mikkelson et al., 2007).

An observational study was conducted at all sites prior to the start of the experimental treatments. Most sites $(N=40)$ were sampled in three replicate blocks each composed of ten $5 \times 5 \mathrm{~m}$ plots for a total of 30 plots per site. Note that at some sites, replication varied: 10 sites had less than 30 plots (range of 10-27 plots per site) and 10 sites had more than 30 plots (range of $31-60$ plots per site). The total data set was composed of 1889 individual observations including variable replication at some sites. While most sites collected data in $2007(N=39)$, data from additional sites were collected in $2008(N=10), 2009(N=3), 2010(N=3), 2011(N=2), 2012$ $(N=3), 2013(N=2)$.

At a subset of the sites $(N=39)$, we conducted a replicated experiment that allowed us to estimate herbivore pressure and nutrient limitation. The experiment was a full factorial combination of nutrient addition (Control or Fertilized) and consumer density (Control or Fenced) for a total of four treatments. Fences were $2.1 \mathrm{~m}$ tall, and designed to exclude large aboveground mammalian herbivores, including ungulates. The first $90 \mathrm{~cm}$ was $1 \mathrm{~cm}$ woven wire mesh with a $30 \mathrm{~cm}$ outward-facing flange stapled to the ground to exclude digging animals; climbing and subterranean animals potentially could access plots. Nutrient addition rates and sources were: $10 \mathrm{~g}$ $\mathrm{N} \mathrm{m}^{-2} \mathrm{yr}^{-1}$ as timed-release urea, $10 \mathrm{~g} \mathrm{P} \mathrm{m}^{-2} \mathrm{yr}^{-1}$ as triplesuper phosphate, $10 \mathrm{~g} \mathrm{~K} \mathrm{~m}^{-2} \mathrm{yr}^{-1}$ as potassium sulfate and $100 \mathrm{~g} \mathrm{~m}^{-2} \mathrm{yr}^{-1}$ of a micronutrient mix $(6 \% \mathrm{Ca}, 3 \% \mathrm{Mg}, 12 \% \mathrm{~S}$, $0.1 \% \mathrm{~B}, 1 \% \mathrm{Cu}, 17 \% \mathrm{Fe}, 2.5 \% \mathrm{Mn}, 0.05 \% \mathrm{Mo}$, and $1 \% \mathrm{Zn}) . \mathrm{N}, \mathrm{P}$, and $\mathrm{K}$ were applied annually; the micronutrient mix was applied once at the start of the study to avoid toxicity of largely immobile micronutrients.

Ammonium nitrate was used as the nitrogen source in 2007, however, urea was used in all subsequent years due to difficulties in procuring ammonium nitrate. We tested whether various nitrogen sources could alter community responses by conducting an experiment comparing the two nitrogen sources (timed-release urea, and ammonium nitrate) at four NutNet sites (Bunchgrass, Hopland, Lookout, and Mclaughlin; Table S1). At each site, we established a fully randomized complete block design with three treatments (Control and $10 \mathrm{~g}$ of $\mathrm{N}$ added as either timed-release urea or ammonium nitrate) and three blocks (nine plots per site and 36 plots total). Each plot was $2 \times 2 \mathrm{~m}$. We applied the treatments in spring 2009 and sampled the cover and biomass of the plots in 2010 as described below. We found no difference in richness or total live biomass among the nitrogen sources based on a mixed-effects model with site and block within site treated as random effects $(P=0.374$ for biomass and $P=1.000$ for richness).

\section{Sampling}

Areal cover of all species was estimated visually to the nearest $1 \%$ in a $1 \mathrm{~m}^{2}$ quadrat in each $5 \times 5 \mathrm{~m}$ plot. Typically there were 30 cover plots per site. Cover was estimated independently for each species so that total summed cover exceeded $100 \%$ for multilayer canopies. At some sites with strongly seasonal communities, cover was estimated twice during the year and the maximum cover of each species was used in the analyses. Lead scientists at each site provided the provenance of each species that occurred at their sites. Across the study sites, some species occurred in both their native and exotic range (Firn et al., 2011). Aboveground biomass was collected in two $10 \times 100 \mathrm{~cm}$ strips $\left(0.2 \mathrm{~m}^{2}\right.$ in each plot) clipped at peak biomass in each $5 \times 5-\mathrm{m}$ plot for an average 30 biomass samples per site. Biomass was sorted to functional group (i.e., grass, forb, legume, bryophyte, litter), and the current year's production was dried to constant mass at $60^{\circ} \mathrm{C}$, and weighed to the nearest $0.01 \mathrm{~g}$.

\section{Statistical analyses}

All analyses were conducted using R version 2.15 (R Development Core Team, 2010). We examined the relationship between exotic richness and cover and the following bioclimatic drivers:

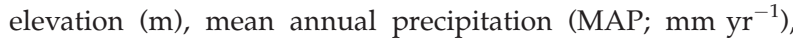
seasonal precipitation variability (coefficient of variation in monthly precipitation), mean annual temperature $(\mathrm{C})$, mean minimum annual temperature $(C)$, mean maximum annual temperature $(\mathrm{C})$, seasonal temperature variability (standard deviation in mean monthly temperature), temperature in the wettest quarter $(\mathrm{C})$, aboveground dead biomass $\left(\mathrm{g} \mathrm{m}^{-2}\right)$, and aboveground live biomass $\left(\mathrm{g} \mathrm{m}^{-2} \mathrm{yr}^{-1}\right)$. We tested whether the richness of local flora (i.e., cumulative number of species at each site) was correlated with exotic establishment or dominance by including site-level native species richness. We also included the richness of native species of different lifespan (annual or perennial) and lifeform (grasses, forbs, and woody plants). There were insufficient data at one site to fully classify species by lifeform and lifespan, and this site was not included in regressions including these variables.

We tested whether exotic richness or cover were related to herbivore pressure or nutrient limitation at each of the experimental sites $(N=39)$ after a single year of treatment (Fencing or Fertilization). We calculated the treatment effects after a single year as the best direct measure of the herbivore effects and nutrient limitation independent of compositional changes and species extinctions that become increasingly important after multiple years of treatments. We estimated herbivore pressure as the change in live biomass resulting from fencing calculated as the $\log$ ratio $\log \left(B_{f-} / B_{f+}\right)$, where $B_{f-}$ is the live biomass in control plots and $B_{f_{+}}$is the live biomass in fenced plots after 1 year of fencing treatment. We estimated nutrient limitation by calculating the change in live biomass resulting from nutrient addition calculated as the $\log$ ratio $\log \left(B_{\text {nut }}\right)$ $\left.B_{\text {nut- }}\right)$, where $B_{\text {nut- }}$ is the live biomass in unfertilized plots and $B_{n u t+}$ is the live biomass in fertilized plots after 1 year of nutrient addition treatments. 
We calculated exotic cover as a relative measure by summing cover of all exotic species and dividing by the summed cover of all species. We modeled the cover of exotic species as a proportion ranging from 0 to 1.0 using generalized linear models with logit link and binomial error (i.e., logistic regression), and modeled exotic richness (number of exotic species per $\mathrm{m}^{2}$ ) using a log link and Poisson errors (i.e., Poisson regression). All regression models started with the following variables: elevation $(\log \mathrm{m})$; precipitation $\left(\mathrm{mm} \mathrm{yr}^{-1}\right)$; seasonal precipitation and temperature variation; mean, maximum, and minimum annual temperature (C); aboveground live biomass ( $\left.\log \mathrm{g} \mathrm{m}^{-2} \mathrm{yr}^{-1}\right)$; aboveground dead biomass $\left(\log \mathrm{g} \mathrm{m}^{-2}\right)$; richness of native species, native annuals, native grasses, native forbs, native woody plants, herbivore pressure (i.e., fencing effect on biomass); nutrient limitation (fertilization effect on biomass); years since last grazing and cultivation; distance to the nearest road, river, cultivated land, and coast; and the population of the nearest town.

We used quasi-likelihood to adjust for over dispersion or underdispersion in the data. It is not possible to calculate AIC or similar likelihood-based statistics from quasi-likelihood models (Venables \& Ripley, 2003), so we reduced the models using backwards selection and Type II sums of squares to include only those variables explaining significant amount of variation using the F statistic. We also conducted the analyses using transformations for the richness (square root) and proportion exotic cover (arcsine square root), and results were qualitatively similar. Finally, we had similar results analyzing the plot-scale data using mixed-effects models with site as a random effect (Pinheiro \& Bates, 2000).

We were missing data on live biomass at 4 sites, fencing and fertilization effects on biomass at 23 sites, and cultivation or grazing history at 26 sites. Biomass, fencing effects, fertilization effects, cultivation history, grazing history, and land-use data were not present in any of the final statistical models (i.e., the parsimonious models after selection), so we present results of models fit to the larger data set excluding these variables. Results did not differ qualitatively across these different subsets of the data.

\section{Results}

Across sites ranging from salt marshes to alpine tundra (Fig. 1; Table S1), we documented 1477 species from 102 families. The 191 exotic species comprised 34 families. We were unable to classify the provenance of 129 taxa due to either taxonomic or provenance uncertainties (9\% of the total species). Unclassified species comprised $7 \%$ of the cover in the total data set, and we have no reason to expect that unclassified species were biased with regard to their provenance. Relative exotic cover (100*exotic cover/total cover) varied from 0 to $100 \%$ at both the plot $(n=1924)$ and site scales $(n=62)$. Exotic richness ranged from 0 to 46 species at the site scale (cumulative exotic richness) and from 0 to 20 species at the plot scale (i.e., mean exotic richness $\mathrm{m}^{-2}$ ). Note that hereafter we only analyze mean exotic

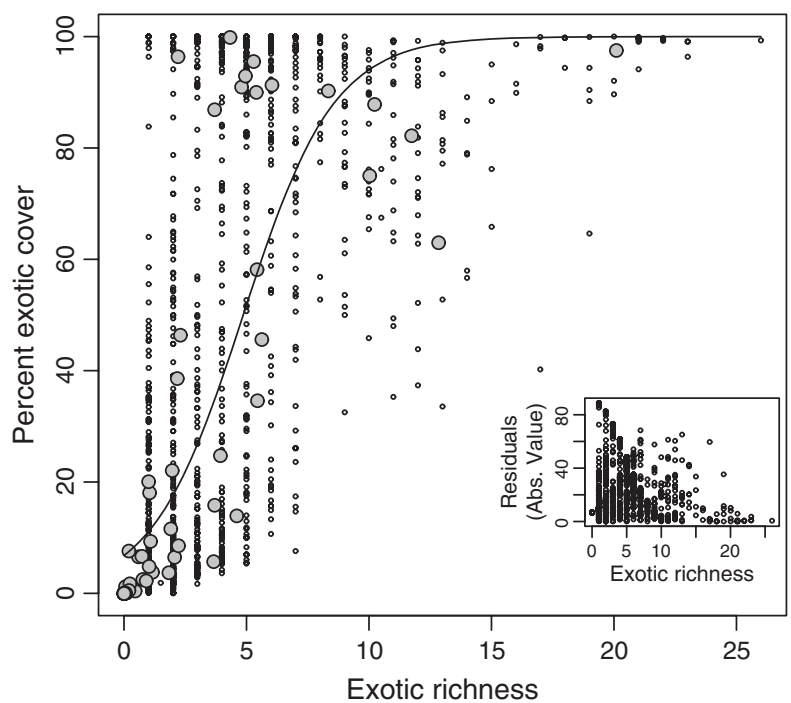

Fig. 2 Logistic regression showing relationship between exotic richness and mean cover of exotic species in 1924 plots in 62 grassland sites in 13 countries. Small open circles are plot-scale data and larger gray circles show site means. Solid line shows predicted relationship based on a logistic regression of the plotscale data for exotic cover and richness $(F=49.5 ; P<0.001)$. Inset shows the absolute value of the regression residuals.

Table 1 Results of logistic regression of exotic cover on exotic richness at the site scale $(N=62)$. Tests of significance are based on quasi-likelihood due to significant underdispersion or overdispersion in the data. Estimated dispersion parameter was 0.52

\begin{tabular}{lllrll}
\hline Source & Estimate & S.S. & df & $F$ & $P$ \\
\hline Exotic richness & 0.5629 & 26.209 & 1 & 50.428 & $<0.0001$ \\
Residuals & & 31.184 & 60 & & \\
\hline
\end{tabular}

richness at the plot scale, as the mean plot-scale richness is highly correlated with cumulative exotic richness across all plots at each site $(r=0.84, P<0.001)$.

Exotic cover and exotic richness were positively correlated at the site and plot scale (Fig. 2; Table 1), however, the relationship was strongly nonlinear. In addition, exotic cover was highly variable at low levels of species richness. For example, while sites with an average of 10 or more exotic species were always dominated by exotic species ( $>80 \%$ exotic cover), sites with less than three exotic species spanned the range from 0 to $96 \%$ exotic cover. As a result of the higher variance in exotic cover at sites with low exotic richness, the residuals around the regressions were much larger at low levels exotic richness (Inset Fig. 2). Thus, exotic richness provides a lower bound on exotic dominance, but exotic richness does not discern between sites with a few sparse invaders (low exotic richness and cover) 
and those dominated by a few highly abundant exotic species (low exotic richness but high exotic cover).

Most of the variability in exotic richness and cover at the plot scale was due to differences among regions and ecosystems; there was almost no variability accounted for by differences among continents (Fig. 3), as even highly invaded continents had areas dominated by native species (e.g., the Central Great Plains of North America; Figs 1 and 4). Exotic cover varied most strongly among regions (44\%). Although exotic richness also had significant variation among regions (30\% of variance), it varied much more among sites within a single ecosystem in a region ( $42 \%$ of variance). In terms of regional variation in exotic cover, all sites in Africa, Asia, and Europe were dominated by native species, as measured by richness or cover, whereas all sites on the Pacific Coast of North America were highly invaded (Fig. 4a). Variation among different ecosystems was equally strong. Alpine, montane, salt marsh, and shrub steppe sites had less than $10 \%$ exotic cover, whereas annual grasslands had more than $75 \%$ exotic cover (Fig. 4b).

In part, these differences among regions and ecosystems reflect underlying biotic, climatic, and human land-use gradients. Site-level means of exotic cover and richness were lowest in areas with a diverse native grass flora (number of grass species at a site) (Fig. 5) and at sites located far from cultivated agricultural fields (Table 2). Exotic cover was also higher in areas with consistent precipitation (low variance among months), and exotic richness was higher at hot (high

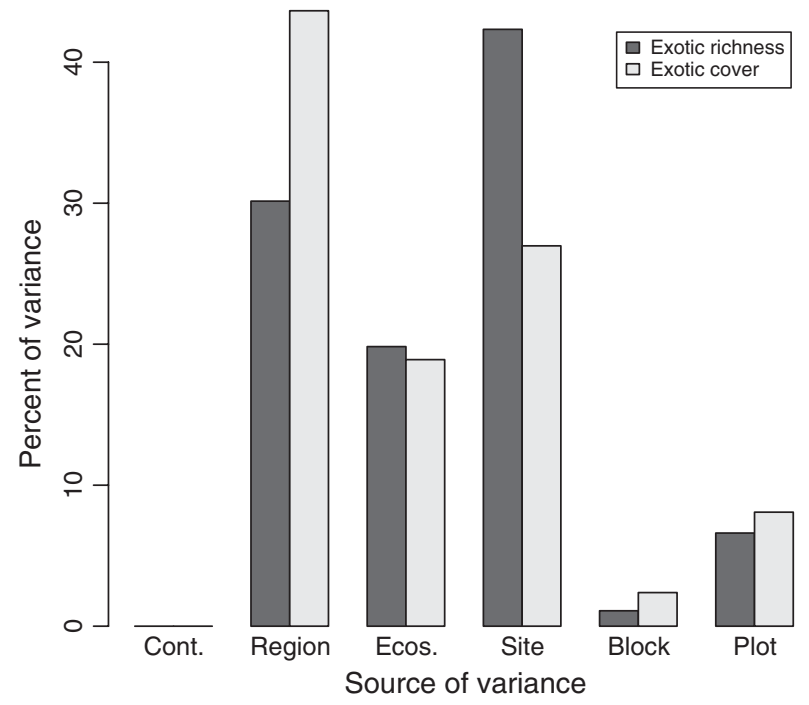

Fig. 3 Variance components analysis showing distribution of variance in exotic richness and exotic cover (percent of total) among 1924 plots sampled at 62 sites in 13 countries. Sources of variation are the following nested terms: continent, region, ecosystem, site, block, and plot (residual) level variation. maximum temperature) sites near the coast that have a cool wet season.

The strong and consistent effects of native grass richness likely reflect the dominance of grasses, as a group. Native grasses comprised the highest percent of native plant cover (mean $=46.9 \% \pm 3.5 \%$ SEM). Forbs were the next most abundant group (mean $=35.1 \% \pm 3.3 \%$ SEM). In contrast, average forb diversity (mean $=16.9$ \pm 1.9 SEM species $\mathrm{m}^{-2}$ ) was higher than grasses $\left(\right.$ mean $=6.2 \pm 0.7 \mathrm{SEM}$ species $\mathrm{m}^{-2}$ ). The strong negative relationship between native grass richness and exotic species cover also could occur if exotic cover and native grass richness were driven by the same underlying factors. To test this possibility, we compared models of exotic cover and native grass richness that did not use the diversity of the native flora as an explanatory variable. Although both responded to climate, the strength and direction of factors controlling native grass richness were different from those driving exotic cover (Table S2), providing little evidence for a shared latent factor.

The following variables were not included in any of the reduced models: minimum annual temperature (C);
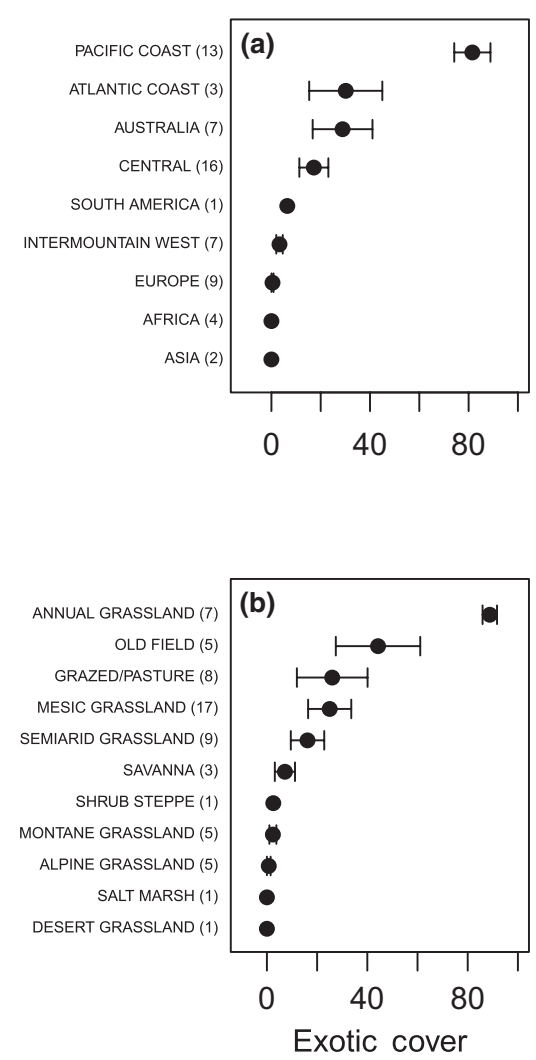

Fig. 4 Exotic cover (percent of total) by region (a) and ecosystem (b) at 62 sites in 13 countries. Pacific Coast, central, Intermountain West, and Atlantic coast are regions within North America. Error bars are 1 SEM and numbers in parentheses are the number of sites in each category. 

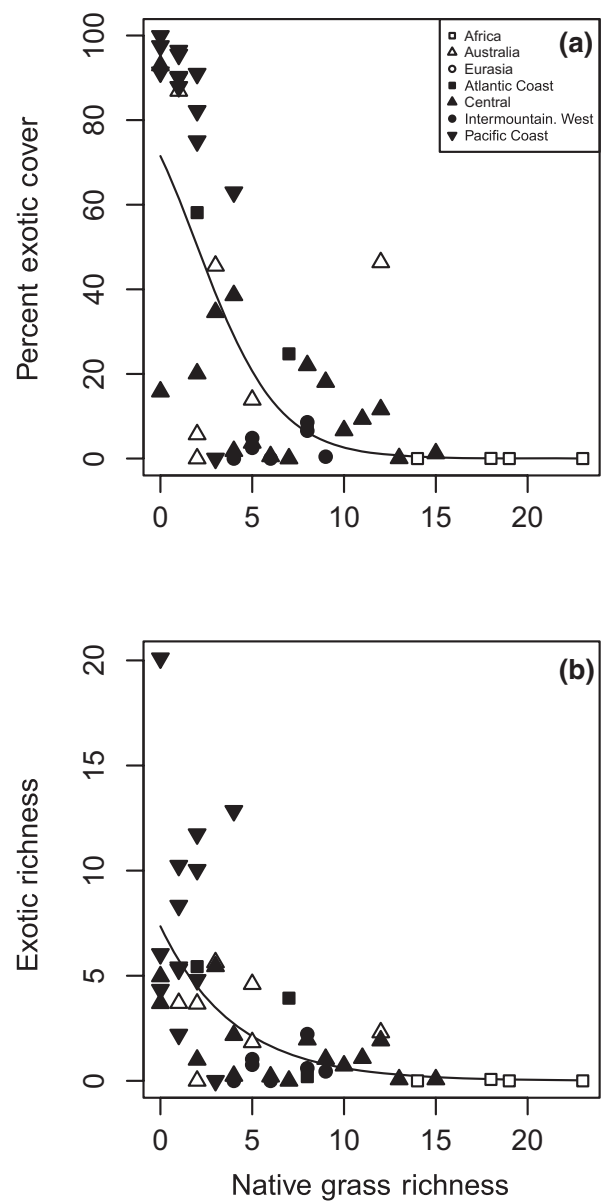

Fig. 5 Regressions showing relationship between mean cover (a) and richness of exotic species and the total richness (b) of native grass species at 62 grassland sites in 13 countries. Regression lines for percent cover are logistic regressions and for richness are Poisson regressions.

aboveground live biomass ( $\log \mathrm{g} \mathrm{m}^{-2} \mathrm{yr}^{-1}$ ); aboveground dead biomass $\left(\log \mathrm{g} \mathrm{m}^{-2}\right)$; richness of native species, native annuals, native grasses, native forbs, native woody plants, herbivore pressure (i.e., fencing effect on biomass); nutrient limitation (fertilization effect on biomass); years since last grazing and cultivation; distance to the nearest road, river; and the population of the nearest town. Thus, while native community flora, climate, and land use all influence exotic cover and richness, only a few of these commonly used factors were ever retained in models. Herbivore pressure and nutrient limitation of productivity were never correlated with global measures of exotic richness or cover.

\section{Discussion}

Using data from a multi-continent, replicated study, we found exotic richness to be an inconsistent predictor of exotic dominance at sites with low exotic richness. Although sites with many exotic species were uniformly exotic dominated, sites with few exotic species could either be largely native or completely dominated by one or two exotic species. In grasslands, much of this variation arose from differences among regions within continents (the Atlantic and Pacific coasts of North America were highly invaded, but the Central Region was not) and ecosystem types (annual grasslands, savannas, pastures, old fields were dominated by exotics). Region and ecosystem type are interrelated. For example, all of the Atlantic coast sites are old fields or savanna and $57 \%$ of the Pacific Coast sites are annual grasslands or savanna. Human land use, native community diversity, and environmental gradients (i.e., climate) were all correlated with invasion. Specifically, the strongest predictor of exotic richness and cover was the number of native grass species present in the site or regional flora, with more native grass species negatively correlated with exotic grass richness. In addition, exotic richness and cover were both higher at sites that were close to cultivated land. Climate also played a role in determining invasion, however, climatic effects were different for exotic and native richness. Exotic cover was highest in sites that had low rainfall seasonality, while exotic richness was highest at sites in hot areas (high maximum temperature) with a pronounced cool and wet season.

Despite the historical and continued focus on exotic richness (Fridley et al., 2007), we found that exotic richness was only an effective predictor of exotic dominance when exotic richness was very high (i.e., greater than 10 exotic species per $\mathrm{m}^{2}$ ). Exotic richness could not resolve the difference between two distinct types of sites with low exotic species richness: those sites that are relatively pristine with a few rare exotic species and those that are dominated by a few highly dominant exotic species. Thus, examination of only exotic richness hinders our understanding of drivers of invasion by confounding these qualitatively different site types, both with low exotic richness. The poor predictive capacity of exotic richness suggests the need for efforts like the work presented here that measure exotic dominance in standard and comparable ways across many sites.

The importance of native grass richness as a predictor of exotic cover suggests that evolutionary history may be a critical component in understanding invasions. Interestingly, it is the diversity of grasses and not diversity per se that appears to mediate the dominance of exotic species. In addition, we find the strongest relationship between exotic cover and cover of the most abundant group of native plants (i.e., grasses) as opposed to the most diverse (i.e., forbs). Exotic grasses 
Table 2 Final regression model of exotic cover and exotic richness at the site scale $(N=62)$ explained by environmental covariates. Tests of significance are based on quasi-likelihood due to significant overdispersion or underdispersion in the data. Only the reduced model is shown. The full model included elevation $(\mathrm{m})$; precipitation $\left(\mathrm{mm} \mathrm{yr}^{-1}\right)$; seasonal precipitation and temperature variation; mean, maximum, and minimum annual temperature (C); aboveground live biomass $\left(\log \mathrm{g} \mathrm{m}^{-2} \mathrm{yr}^{-1}\right.$ ); aboveground dead biomass $\left(\log \mathrm{g} \mathrm{m}^{-2}\right)$; richness of native species, native annuals, native grasses, native forbs, native woody plants, herbivore pressure (i.e., fencing effect on biomass); nutrient limitation (fertilization effect on biomass); years since last grazing and cultivation; distance to the nearest road, river, cultivated land, and coast; and the population of the nearest town. Estimated dispersion parameter for quasi-likelihood was 0.70 for exotic cover and 2.15 for exotic richness

\begin{tabular}{|c|c|c|c|c|c|c|}
\hline Response & Source & Estimate & S.S. & $\mathrm{df}$ & $F$ & $P$ \\
\hline \multirow[t]{4}{*}{ Exotic cover } & Native grass richness & -0.362 & 16.92 & 1 & 24.3 & 0.000 \\
\hline & Precipitation variation & 0.050 & 6.93 & 1 & 10.0 & 0.003 \\
\hline & Distance to cultivation & -1.022 & 3.37 & 1 & 4.8 & 0.032 \\
\hline & Residuals & & 39.62 & 57 & & \\
\hline \multirow[t]{6}{*}{ Exotic richness } & Native grass richness & -0.163 & 36.93 & 1 & 17.2 & 0.000 \\
\hline & Distance to coast & -0.511 & 22.03 & 1 & 10.3 & 0.002 \\
\hline & Maximum temperature & 0.117 & 20.56 & 1 & 9.6 & 0.003 \\
\hline & Temp. wettest quarter & -0.048 & 9.44 & 1 & 4.4 & 0.041 \\
\hline & Distance to cultivation & -0.338 & 9.44 & 1 & 4.4 & 0.041 \\
\hline & Residuals & & 118.20 & 55 & & \\
\hline
\end{tabular}

are particularly effective invaders and tend to be more abundant in their invasive range (Firn et al., 2011), and colonization by new species can be impeded by presence of resident species that are functionally similar (Fargione et al., 2003). Regions that have evolved diverse grass floras may be more likely to contain native species that overlap the niches of a particularly effective group of invaders (i.e., grasses), conferring invasion resistance. Ultimately, drawing inferences about diversity-invasibility relationships using observational data requires caution, because of possible covariates that may confound causal native exotic richness relationships (Rejmanek, 2003; Fridley et al., 2007).

Given the wide range of environmental conditions spanned by this study and the diversity of exotic taxa represented across these sites, we did not expect to find consistent environmental drivers of exotic species richness and cover. Nevertheless, we did find that both exotic cover and richness were increased by the propinquity of cultivated lands. In addition, exotic richness was higher in coastal areas. Human endeavors, including agriculture, undoubtedly increase invasion as has been shown in many other studies (Antonelli et al., 2011; Davis et al., 2000; Gelbard \& Harrison, 2003; Gonzalez et al., 2010, Mack, 1989; Parker et al., 2006; Rejmanek, 2003; Scott et al., 2001; Seabloom et al., 2009, 2006; Taylor \& Irwin, 2004; Williams et al., 2005).

Studies replicated at the regional, as opposed to the global scale, have found higher exotic richness in lowlying coastal areas (Rejmanek, 2003; Williams et al., 2005; Seabloom et al., 2006; Alexander et al., 2011); however, indirect factors like coastal proximity and elevation are often highly correlated with many potential invasion-drivers including native richness, species introduction rates, ecosystem productivity, human population, and conversion of land to human-dominated uses (Balmford et al., 2001; Scott et al., 2001; Seabloom et al., 2002, 2006; Rejmanek, 2003; Williams et al., 2005). While we found more exotic species at sites near coastlines, elevation was not included in the best model of exotic dominance or richness.

We did not find a detectable impact of large herbivore pressure on exotic occurrence and dominance. However, other studies have shown that preferential consumption of native plants by herbivores may increase invasions (Orrock et al., 2008, 2009; Seabloom et al., 2009), although the strength and direction of herbivore effects are contingent upon the amount of shared evolutionary history between herbivores and plants (Mack, 1989; Parker et al., 2006; Verhoeven et al., 2009). At a broader scale, the areas in this study that are highly invaded are concordant with those highlighted by Mack (1989) as possibly lacking an evolutionary history with congregating, hoofed grazers during the Holocene, such as Australia and the Pacific Coast of North America. In contrast, sites with high native grass diversity and low cover of exotics have a long history of grazing by hoofed mammals, such as Eurasia, Africa, and the Central Great Plains of North America (Mack, 1989).

Although it is clear that biological invasions have altered many of the world's ecosystems and precipitate significant economic costs (Vitousek, 1990; Lodge, 1993; Mills et al., 1994; Seabloom \& Wiedemann, 1994; Vitousek et al., 1997; Levine et al., 2003; Pimentel et al., 2005), we still have little ability to make general predictions about which species will have the greatest impacts as invaders and which areas are likely to be the most 
impacted (Parker et al., 1999; Seabloom et al., 2003; Firn et al., 2011; Catford et al., 2012). The search for general drivers of invasion at the global scale has been hindered by the lack of consistent, globally replicated data on exotic abundance, and a resulting overemphasis on exotic richness as a surrogate for impact. Here we show that exotic richness is only an effective predictor of exotic dominance when richness is exceptionally high; overall, exotic richness represents a poor proxy for the impact, assessed here via exotic cover, of exotic species on native communities. Our global-scale observations bridge the gap between mechanistic studies at single sites and meta-analyses of global patterns of exotic richness, shedding new light on the drivers and outcomes of global invasions.

\section{Acknowledgements}

This work was generated using data from the Nutrient Network (http://nutnet.org) experiment, funded at the site scale by individual researchers. Coordination and data management have been supported by funding to E. Borer and E. Seabloom from the National Science Foundation Research Coordination Network (NSF-DEB-1042132) and Long Term Ecological Research (NSF-DEB-1234162 to Cedar Creek LTER) programs and the Institute on the Environment (DG-0001-13). We also thank the Minnesota Supercomputer Institute for hosting project data and the Institute on the Environment for hosting Network meetings. Supplemental table S3 provides information on author roles. Any use of trade names is for descriptive purposes only and does not imply endorsement by the U.S. Government.

\section{References}

Alexander JM, Kueffer C, Daehler CC, Edwardsa PJ, Pauchard A, Seipel T, Consortiuma M (2011) Assembly of nonnative floras along elevational gradients explained by directional ecological filtering. Proceedings of the National Academy of Science USA, 108, 656-661.

Antonelli A, Humphreys AM, Lee WG, Linder HP (2011) Absence of mammals and the evolution of New Zealand grassesProceedings Royal Society B, 278, 695-701.

Balmford A, Moore JL, Brooks T, Burgess N, Hansen LA, Williams P, Rahbek C (2001) Conservation conflicts across Africa. Science, 291, 2616-2619.

Candolle APD, Sprengel KPJ (1821) Elements of the Philosophy of Plants: Containing the Principles of Scientific Botany with a History of the Science, and Practical Illustrations.W. Blackwood, Edinburgh.

Catford JA, Vesk PA, Richardson DM, Pysek P (2012) Quantifying levels of biological invasion: towards the objective classification of invaded and invasible ecosystems. Global Change Biology, 18, 44-62.

Chapin FS, Matson PA, Mooney HA (2002) Principles of Terrestrial Ecosystem Ecology. Springer, New York.

Conant RT (2010) Challenges and Opportunities for Carbon Sequestration in Grassland Systems: A Technical Report on Grassland Management and Climate Change Mitigation. Food and Agriculture Organization of the United Nations (FAO), Rome, Italy.

Crawley MJ (1987) What makes a community invasible? In: Colonization, Succession, and Stability: the 26th Symposium of the British Ecological Society held jointly with the Linnean Society of London (eds Gray AJ, Crawley MJ, Edwards PJ), pp. 429-454. Blackwell Scientific Publications, Oxford Oxfordshire, Boston.

Darwin CA (1859) On the origin of species by means of natural selection. or the preservation of favoured races in the struggle for life. John Murray, Albermarle Street, London.

Davis MA (2003) Biotic globalization: does competition from introduced species threaten biodiversity? BioScience, 53, 481-489.

Davis MA, Grime JP, Thompson K (2000) Fluctuating resources in plant communities: a general theory of invasibility. Journal of Ecology, 88, 528-534.
Elton CS (1958) The Ecology of Invasions by Animals and Plants. Methuen, London, England.

Fargione J, Brown CS, Tilman D (2003) Community assembly and invasion: an experimental test of neutral versus niche processes. Proceedings of the National Academy of Sciences of the United States of America, 100, 8916-8920.

Firn J, Moore JL, Macdougall AS, Borer ET, Seabloom EW, Hillerislambers J, Buckley YM (2011) Abundance of introduced species at home predicts abundance away in herbaceous communities. Ecology Letters, 14, 274-281.

Forman RTT, Alexander LE (1998) Roads and their major ecological effects. Annual Review of Ecology and Systematics, 29, 207-231.

Fridley JD, Brown RL, Bruno JE (2004) Null models of exotic invasion and scaledependent patterns of native and exotic species richness. Ecology, 85, 3215-3222.

Fridley JD, Stachowicz JJ, Naeem S, Sax DF, Seabloom EW, Smith MD, Von Holle B (2007) The invasion paradox: reconciling pattern and process in species invasions. Ecology, 88, 3-17.

Gelbard JL, Harrison S (2003) Roadless habitats as refuges for native grassland diversity. Ecological Applications, 13, 404-415.

Gonzalez AL, Kominoski JS, Danger M, Ishida S, Iwai N, Rubach A (2010) Can ecological stoichiometry help explain patterns of biological invasions? Oikos, 119, 779-790.

Grime JP (1998) Benefits of plant diversity to ecosystems: immediate, filter and founder effects. Journal of Ecology, 86, 902-910.

Henwood WD (2010) Toward a strategy for the conservation and protection of the world's temperate grasslands. Great Plains Research, 20, 121-134.

Hijmans RJ, Cameron SE, Parra JL, Jones PG, Jarvis A (2005) Very high resolution interpolated climate surfaces for global land areas. International Journal of Climatology, 25, 1965-1978.

Hoekstra JM, Boucher TM, Ricketts TH, Roberts C (2005) Confronting a biome crisis: global disparities of habitat loss and protection. Ecology Letters, 8, 23-29.

Huenneke LF, Hamburg SP, Koide R, Mooney HA, Vitousek PM (1990) Effects of soil resources on plant invasion and community structure in Californian serpentine grassland. Ecology, 71, 478 491.

Hurlbert SH (1997) Functional importance vs keystoneness: reformulating some questions in theoretical biocenology. Australian Journal of Ecology, 22, 369-382.

Levine JM, D'Antonio CM (2003) Forecasting biological invasions with increasing international trade. Conservation Biology, 17, 322-326.

Levine JM, Vila M, D'antonio CM, Dukes JS, Grigulis K, Lavorel S (2003) Mechanisms underlying the impacts of exotic plant invasions. Proceedings of the Royal Society of London Series B-Biological Sciences, 270, 775-781.

Lodge DM (1993) Biological invasions: lessons for ecology. Trends in Ecology \& Evolution, 8, 133-137.

Mack RN (1989) Temperate grasslands vulnerable to plant invasion: characteristics and consequences. In: Biological Invasion: A Global Perspective (eds Drake JA, Mooney HA, Dicastri F, Groves RH, Kruger FJ, Rejmanek M, Williamson M), pp. 155-179. John Wiley and Sons, NewYork, New York, USA

Mack RN (2003) Plant naturalizations and invasions in the eastern United States: 1634-1860. Annals of the Missouri Botanical Garden, 90, 77-90.

Mack RN, Thompson JN (1982) Evolution in steppe with few large, hoofed mammals. American Naturalist, 119, 757-773.

Melbourne BA, Cornell HV, Davies KF, Dugaw CJ, Elmendorf S, Freestone AL, Yokomizo H (2007) Invasion in a heterogeneous world: resistance, coexistence or hostile takeover? Ecology Letters, 10, 77-94.

Mikkelson GM, Gonzalez A, Peterson GD (2007) Economic inequality predicts biodiversity loss. PLOS ONE, 2, e444.

Mills EL, Leach JH, Carlton JT, Secor CL (1994) Exotic species and the integrity of the Great Lakes: lessons from the past. BioScience, 44, 666-676.

Mooney HA, Cleland EE (2001) The evolutionary impact of invasive species. Proceedings of the National Academy of Sciences of the United States of America, 98, 5446-5451.

Olson DM, Dinerstein E, Wikramanayake ED, Burgess ND, Powell GVN, Underwood EC, Kassem KR (2001) Terrestrial ecoregions of the worlds: a new map of life on Earth. BioScience, 51, 933-938.

Orrock JL, Witter MS, Reichman OJ (2008) Apparent competition with an exotic plant reduces native plant establishment. Ecology, 89, 1168-1174.

Orrock JL, Witter MS, Reichman OJ (2009) Native consumers and seed limitation constrain the restoration of a native perennial grass in exotic habitats. Restoration Ecology, 17, 148-157.

Parker IM, Simberloff D, Lonsdale WM, Goodell K, Wonham M, Kareiva PM, Goldwasser L (1999) Impact: toward a framework for understanding the ecological effects of invaders. Biological Invasions, 1, 3-19.

Parker JD, Burkepile DE, Hay ME (2006) Opposing effects of native and exotic herbivores on plant invasions. Science, 311, 1459-1461. 
Pimentel D, Zuniga R, Morrison D (2005) Update on the environmental and economic costs associated with alien-invasive species in the United States. Ecological Economics, 52, 273-288.

Pinheiro JC, Bates DM (2000) Mixed Effects Models in S and S-Plus. Springer-Verlag, New York.

Qian H, Ricklefs RE (2006) The role of exotic species in homogenizing the North American flora. Ecology Letters, 9, 1293-1298.

R Development Core Team (2010) R: A Language and Environment for Statistical Computing. R Foundation for Statistical Computing, Vienna, Austria.

Ramankutty N, Evan AT, Monfreda C, Foley JA (2008) Farming the planet: 1. Geographic distribution of global agricultural lands in the year 2000. Global Biogeochemical Cycles, 22, 1-19.

Rejmanek M (2003) The rich get richer - responses. Frontiers in Ecology and the Environment, 1, 122-123

Sax DF, Brown JH (2000) The paradox of invasion. Global Ecology and Biogeography, 9 , 363-371.

Sax DF, Gaines SD, Brown JH (2002) Species invasions exceed extinctions on islands worldwide: a comparative study of plants and birds. American Naturalist, 160, 766-783.

Scott JM, Davis FW, Mcghie RG, Wright RG, Groves C, Estes J (2001) Nature reserves: do they capture the full range of America's biological diversity? Ecological Applications, 11, 999-1007.

Seabloom EW (2007) Compensation and the stability of restored grassland communities. Ecological Applications, 17, 1876-1885.

Seabloom EW, Wiedemann AM (1994) Distribution and effects of Ammophila-breviligulata Fern (American beachgrass) on the foredunes of the Washington coast. Journal of Coastal Research, 10, 178-188.

Seabloom EW, Dobson AP, Stoms DM (2002) Extinction rates under nonrandom patterns of habitat loss. Proceedings of the National Academy of Sciences of the United States of America, 99, 1129-11234.

Seabloom EW, Harpole WS, Reichman OJ, Tilman D (2003) Invasion, competitive dominance, and resource use by exotic and native California grassland species. Proceedings of the National Academy of Sciences of the United States of America, 100, 13384-13389.

Seabloom EW, Bjornstad ON, Bolker BM, Reichman OJ (2005) The spatial signature of environmental heterogeneity, dispersal, and competition in successional grasslands. Ecological Monographs, 75, 199-214.

Seabloom EW, Williams JW, Slayback D, Stoms DM, Viers JH, Dobson AP (2006) Human impacts, plant invasion, and imperiled, plant species in California. Ecological Applications, 16, 1338-1350.

Seabloom EW, Borer ET, Martin BA, Orrock JL (2009) Effects of long-term consumer manipulations on invasion in oak savanna communities. Ecology, 90, 1356-1365.

Shea K, Chesson P (2002) Community ecology theory as a framework for biological invasions. Trends in Ecology \& Evolution, 17, 170-176.
Small C, Cohen JE (2004) Continental physiography, climate, and the global distribution of human population. Current Anthropology, 45, 269-277.

Stohlgren TJ, Barnett DT, Kartesz JT (2003) The rich get richer: patterns of plant invasions in the United States. Frontiers in Eccology and the Environment, 1, $11-14$

Taylor BW, Irwin RE (2004) Linking economic activities to the distribution of exotic plants. Proceedings of the National Academy of Sciences of the United States of America, 101, 17725-17730.

Van Kleunen M, Weber E, Fischer M (2011) A meta-analysis of trait differences between invasive and non-invasive plant species. Ecology Letters, 13, 235-245.

Venables WN, Ripley BD (2003) Modern Applied Statistics with S. Springer-Verlag, New York

Verhoeven KJF, Biere A, Harvey JA, Van Der Putten WH (2009) Plant invaders and their novel natural enemies: who is naive? Ecology Letters, 12, 107-117.

Vitousek PM (1990) Biological invasions and ecosystem processes: towards an integration of population biology and ecosystem studies. Oikos, 57, 7-13.

Vitousek PM, D'Antonio CM, Loope LL, Rejmanek M, Westbrooks R (1997) Introduced species: a significant component of human-caused global change. New Zealand Journal of Ecology, 21, 1-16.

Von Humboldt A (1805) Essay on the geography of plants. In: Foundations of Biogeography: Classic Papers with Commentaries (eds Lomolino MV, Sax DF, Brown JH), pp. 49-57. University of Chicago Press, Chicago.

Williams JW, Seabloom EW, Slayback D, Stoms DM, Viers JH (2005) Anthropogenic impacts upon plant species richness and net primary productivity in California Ecology Letters, 8, 127-137.

\section{Supporting Information}

Additional Supporting Information may be found in the online version of this article:

Table S1. Study sites included in analyses. Pretreatment observational data were collected at all sites.

Table S2. Final regression model of exotic cover and exotic richness at the site scale $(N=62)$ explained by environmental covariates.

Table S3. Author contributions to manuscript. 